\title{
CONGENITAL ANOMALIES ASSOCIATED WITH FAILED MISOPROSTOL TERMINATION OF PREGNANCY
}

\author{
Roshan Ara Qazi
}

\begin{abstract}
Misoprostol exposure in the first trimester of pregnancy has been related to congenital malformations, particularly the mobius sequence and terminal transverse limb defects. An unusual case of a 25-years old primigravida who was exposed to misoprostol at 8-weeks gestation is presented here. Failing to medical termination, the pregnancy continued and a live baby girl was delivered preterm at 35-weeks gestation with multiple anomalies like fronto-nasal bone, scalp defects and protrusion of duramater. Microcephaly and equinovarus deformities were also present. Hence, clinicians must be aware of the teratogenic risk of misoprostol with especial context to its unsuccessful use in the first trimester of pregnancy. For the ongoing pregnancies, patient must also be informed in detail.
\end{abstract}

KEY WORDS: Misoprostol. First trimester exposure. Teratogenicity. Cranial bone and scalp defect.

\section{INTRODUCTION}

Misoprostol is a synthetic analogue of prostaglandin $E_{1}$ and is used in the prophylaxis and treatment of peptic ulcer disease. It is also used by women to induce abortion in places where safe elective abortion is not legally available. ${ }^{1}$ An association has been observed between maternal unsuccessful use of misoprostol to induce abortion early in pregnancy and the subsequent birth of a child with congenital anomalies such as Mobiu's anomaly, transverse limb reduction defects, arthrogryposis, multiplex congenita, talepes equinovarus and gastroschisis. ${ }^{2}$ Frontotemporal, frontal bone and scalp defects have been reported from Brazil. $^{3}$ These anomalies are thought to result from vascular disruption induced in the embryo or foetus by misoprostol. ${ }^{4,5}$

Misoprostol has been introduced for only last few years in Pakistan as a cervical ripening agent for late first trimester and mid trimester pregnancy terminations mainly for therapeutic reasons. ${ }^{6}$ It is used for induction of labour as well. ${ }^{7}$ Its strong abortificient effect has definitely been observed by the clinicians and its misuse is very likely in a country like ours where abortion is not legalised yet. Many times women themselves request for termination of unwanted pregnancies. In the case being reported, the woman had been exposed to misoprostol in the first trimester on her own request somewhere and failure to that, without knowing the consequences, the pregnancy had been continued resulting in birth of a congenitally malformed baby in our department.

\section{CASE REPORT}

The case reported here was a 25 years old primigra- vida who had been exposed to misoprostol at 8-weeks gestation for the termination of unwanted pregnancy probably due to adverse socioeconomic status of the couple. She had taken $800-\mathrm{mg}$ of misoprostol orally in divided doses over two days. Failure to medical termination, the couple decided to continue the pregnancy. An ultrasound scan was performed which showed a live pregnancy of eight weeks. The woman had never received any antenatal care and no ultrasound had ever been performed afterwards. She presented to the Department of Obstetrics and Gynaecology of Liaquat University Hospital, Hyderabad - Pakistan at 35-weeks gestation in early preterm labour, which had been postponed with Ritodrine infusion and Dexamethasone rescue was given. Her blood group was ' $B$ ' Rh positive, haemoglobin $10 \mathrm{~g} / \mathrm{dl}$ and random blood sugar was $110 \mathrm{mg} / \mathrm{dl}$. A family history for diabetes mellitus and congenitally malformed babies was absent. She had taken iron and calcium tablets on her own during the third trimester. She underwent an established labour after 24-hours and delivered a live malformed baby girl with frontonasal bone, scalp defect and protrusion of duramater. The baby was low birth weight $(1.7 \mathrm{~kg})$. She had microcephaly and mild right sided equinovarus as well (Figures I and II). Baby's 1 and 5 minute Apgar scores were 7 and 9 respectively. She was subsequently dealt by the paediatric surgeon, who had attempted to cover the cranial and scalp defects at the age of 2-months. The baby had developed convulsions and hydrocephalus afterwards. She had undergone two more corrective surgeries but could not survive and died at the age of 19-months.

\section{DISCUSSION}

About $10 \%$ of congenital anomalies are caused by 
effects of exogenous factors on the developing embryo or foetus. ${ }^{8}$ Although, this is a relatively small subgroup, it is especially important because these congenital anomalies are potentially preventable. ${ }^{4}$ Pregnancy and misoprostol have very enthusiastically remained the subject of discussion by the obstetricians although, misoprostol, a $\mathrm{PGE}_{1}$ analogue, was developed for the treatment of peptic ulcer by Searle in 1973. The drug came before the Advisory Committee of the United States Food and Drug Administration (FDA) in 1985 . $^{9}$ It was felt by one reviewer that the gastrointestinal effects were overshadowed by the abortifacient effect of the drug and he warned of the potential for inadvertent or deliberate misuse by pregnant women. And so it turned out in Brazil, where in the absence of legalised abortion, there was wide spread abuse over a number of years for the purpose of inducing illegal abortions. The therapeutic potential of misoprostol as an abortifacient was clearly demonstrated in 1987 in a randomised study. Subsequent studies, many carried out in France and United Kingdom, have since indicated its efficacy in this respect. Its use both orally and vaginally for first and second trimester regimens for medical evacuation of uterus is being practised around the world. ${ }^{10,11}$ The drug's extremely low cost and stability at room temperature has made it particularly useful in the developing countries like Pakistan. ${ }^{12}$ The drug is easily available over the counter with a great chance to be misused by the medical professionals as well as women themselves.

The teratogenic effects of misoprostol were reported by the Latin American Collaborative Study of Congenital Malformations during 1991-1992. An association between misoprostol use and constriction defects in the foetal limbs has been noticed. ${ }^{13}$ In a study conducted at Brazil, 42 children who were exposed to misoprostol, born with a congenital abnormality. Among these, 17 children had equinovarus with cranial nerve deficiencies, 10 had equinovarus as part of more extensive arthrogryposis and 5 had terminal transverse limb defects. Congenital hydrocephalus was present in 8 children. Another epidemiological study from Brazil has confirmed the association of at least 15 congenital abnormalities with misoprostol misuse in first trimester. The defects seemed to be of vascular disruption type. ${ }^{14}$ The most commonly taken dose of misoprostol was 800-mg (range 200-1600 $\mathrm{mg}){ }^{2}$ Three cases of unusual congenital malformations of the scalp and cranium with exposure of the cerebrum and duramater occurred in newborns exposed to misoprostol in first trimester over a period of 5-months in Fortaleza, Brazil. ${ }^{3}$ Our patient had been exposed to 800-mg oral misoprostol in the first trimester of pregnancy. In the absence of a relevant family history and otherwise being a young and healthy non- diabetic woman who had not taken other abortifacient drugs, it can easily be speculated that the cause of these similar vascular disruption type of congenital anomalies here was a fairly high dose of oral misoprostol as is being reported in the literature. In the present case, the couple opted for termination of pregnancy because of their adverse socio-economic condition. Failure to medical termination, the woman had not gone for surgical termination because she and the prescribing doctor both were probably unaware of the teratogenic effects of the drug resulting in the birth of a baby with multiple anomalies and subsequent painful death of a 19-month old child.

\section{FIGURES I AND II:}

\section{FRONTONASAL BONE AND SCALP DEFECT WITH PROTRUSION OF DURAMATER}
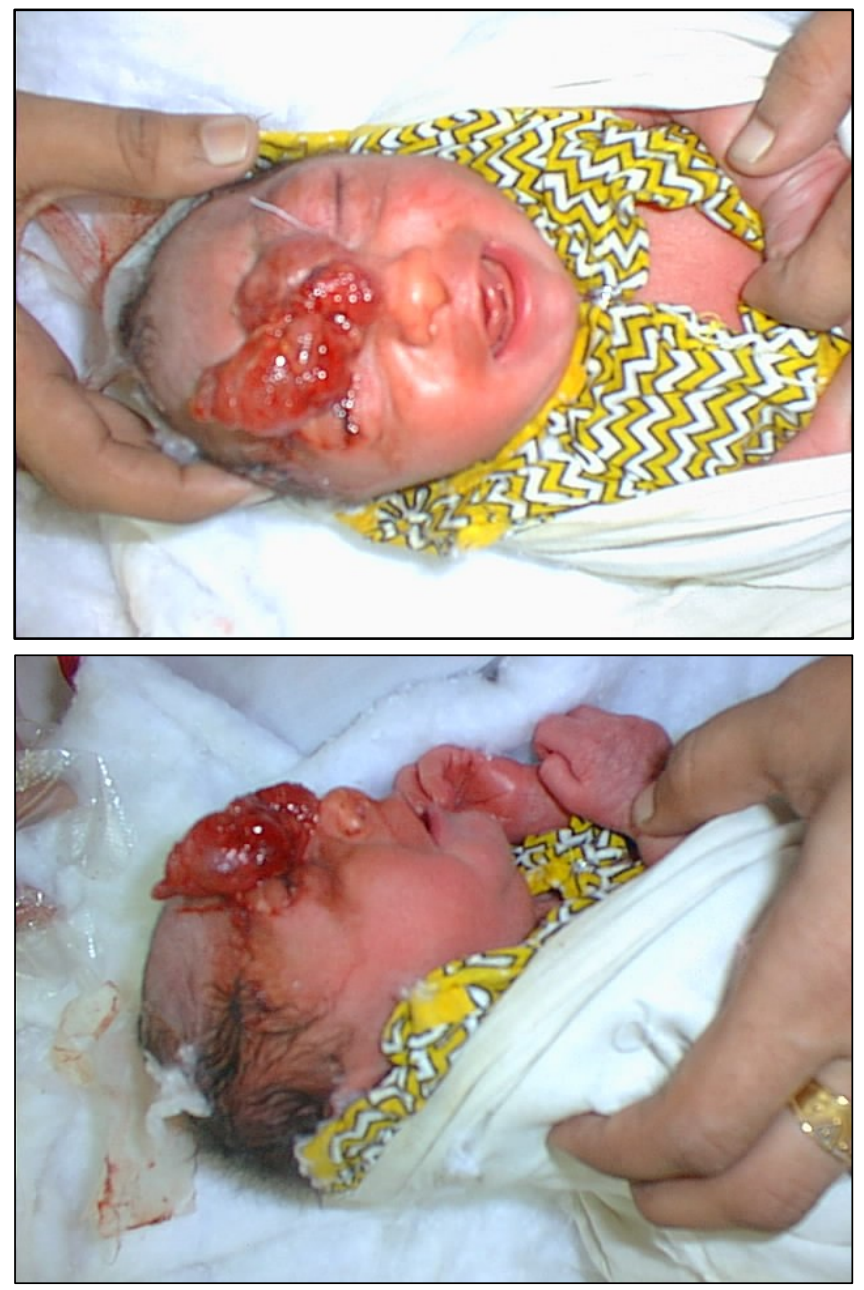

\section{CONCLUSION}

Frontonasal bone and scalp defects are rare anomalies associated with misoprostol misuse in the first trimester pregnancy. The clinicians must be alerted in using misoprostol for first trimester terminations. Fail- 
ure to that, very high risk of associated teratogenicity must be kept in mind. The women shall also be clearly counselled about the consequences, as well as regarding option for surgical termination.

\section{REFERENCES}

1. Grimes DA. Medical abortion in early pregnancy: a review of the evidence. Obstet Gynaecol. 1997;89:790-6.

2. Gonzalez CH, Marques-Dias MJ, Kim CA, Sugayama SM, Da Paz JA, Huson SM, et al. Congenital abnormalities in Brazilian children associated with misoprostol misuse in first trimester of pregnancy. Lancet. 1998;351:1624-7.

3. Fonseca W, Alencar AJC, Mota PSB, Coelho HLL. Misoprostol and congenital malformations. Lancet. 1991;338:56.

4. Polifka JE, Friedman JM. Clinical teratology: identifying teratogenic risks in humans. Clin Genet. 1999;56:409-20.

5. Marques-Dias MJ, Gonzalez LH, Rosemberg S. Mobius sequence in children exposed in vitro to misoprostol: neuropathological study of three cases. Birth Defects Res A Clin Mol Teratol. 2003;67:1002-7.

6. Hossain N, Soomro N, Umar A. Medical management of second trimester fetal demise using Misoprostol. J Coll Physicians Surg Pak. 2002;12: 735-7.

7. Kallue UR, Sultana N. Vaginal Misoprostol - the revolutionary starter switch in induction of labor. Pak Armed Forces Med J. 2004;54:202-4.

8. Brent RL. The application of the principles of toxicology and teratology in evaluating the risks of new drugs for treatment of drug addiction in women of reproductive age. NIDA Res Monogr. 1995;149:130-84.

9. Lewis $\mathrm{JH}$. Summary of the $29^{\text {th }}$ meeting of the Gastrointestinal Drugs Advisory Committee, Food and Drug Administration - June 10, 1985. Am J Gastroenterol. 1985;89:743-5.

10. Templeton A. Misoprostol for all? Br J Obstet Gynaecol. 1998;105:937-9.

11. Quddusi H, Anwar S. Comparison of Misoprostol and PGF2 $\alpha$ for second trimester termination of pregnancy. Ann King Edward Med Coll. 2004;10:311-3.

12. Javed L, Malik M, Jamal N, Sheikh S, Farzana F. Mid-trimester termination of pregnancy - comparison of sublingual with vaginal Misoprostol. Biomedica. 2004;20:56-9.

13. Castilla EE, Orioli IM. Teratogenicity of misoprostol: data from the Latin American Collaborative Study of Congenital Malformations (ECLAMC). Am J Med Genet. 1994;51:161-2.

14. Orioli IM, Castilla EE. Epidemiological assessment of Misoprostol teratogenicity. $\mathrm{Br} \mathrm{J}$ Obstet Gynaecol. 2000; 107:519-23.

\begin{tabular}{|l|}
\hline AUTHOR AFFILIATION: \\
Prof. Roshan Ara Qazi \\
Department of Obstetrics and Gynaecology (Unit IV) \\
Liaquat University of Medical and Health Sciences \\
Jamshoro - Pakistan.
\end{tabular}

